\title{
Information Interactive Design as a Discipline in the Professional Training of a Modern Graphic Designer
}

\author{
Iryna I. Tsidylo ${ }^{1}$, Volodymyr G. Cherniyavskyi², Nataliia V. Barna ${ }^{3}$, Lesia V. Smyrna ${ }^{4}$ \& Valentyna M. \\ Medvedyeva $^{5}$
}

${ }^{1}$ Department of Fine Arts, Design and Methods of Their Teaching, Faculty of Arts, Ternopil Volodymyr Hnatyuk National Pedagogical University, Ternopil, Ukraine

${ }^{2}$ Department of Theory, History of Architecture and Synthesis of Arts, Faculty of Architecture, National Academy of Fine Arts and Architecture (NAOMA), Kyiv, Ukraine

${ }^{3}$ Open International University of Human Development "Ukraine", Kyiv, Ukraine

${ }^{4}$ International Scientific and Artistic Department, National Academy of Arts of Ukraine, Kyiv, Ukraine

${ }^{5}$ Kyiv National University of Culture and Arts, Kyiv, Ukraine

Correspondence: Iryna I. Tsidylo, Ternopil Volodymyr Hnatyuk National Pedagogical University, 2 Maxyma Kryvonosa str., Ternopil, 46027, Ukraine.

Received: June 10, 2020

Accepted: August 3, 2020

Online Published: August 14, 2020

doi:10.5430/ijhe.v9n7p387

URL: https://doi.org/10.5430/ijhe.v9n7p387

\begin{abstract}
The rapid progress of graphic design due to the integration of technology is transforming curricula. Changes take place through the development of disciplines that shape the new skills of the graphic designer in accordance with the needs of the labor market. In this article, based on the content analysis of the official websites of 4 universities of Ukraine and the study of the needs of the labor market in the field of graphic design, the state of use of approaches to teaching graphic design has been revealed. The basis of the study is "a wild theory of technologically facilitated behavioral change" of Rogers. The analysis confirms the hypothesis that approaches to learning are formed in response to the needs of the labor market; they transform curricula. Transformation takes place in the direction of the formation of technical skills, as a consequence of the integration of technologies, and creativity, as a consequence of the need to influence the consumer of the information message through the design product. It has been revealed that the specifics of the Ukrainian labor market determines the offer of educational services in the field of graphic design. The skills required by design product developers are formed in the process of training a graphic designer. It has been proved that the professional competences of a graphic designer meet the needs of the labor market; however, they lag behind new concepts, approaches to the requirements of product creation. The idea of Ukrainian graphic design as a discipline involves forming a competent professional with technical, creative skills for the development of business-oriented products in the field of graphic design. It has been revealed that a systematic and integrated approach is used in the process of training a graphic designer, which correspond to manipulative, ecological approaches as the main theories of creating a graphic product. It has been proved that the theory of "wild design" is not reflected in the modern practice of teaching disciplines within a framework of the specialization "graphic design". This is due to the lack of understanding for the development of such disciplines that would provide the formation of skills in the process of creating a "wild product".
\end{abstract}

Keywords: visual communication, interdisciplinary information design, screen graphic design

\section{Introduction}

Design as a global, universal creative phenomenon is qualitatively divided by scientists into categories. The artistic achievements of design, achieved throughout the history of mankind, are seen by scientists in one holistic historical and cultural phenomenon. Scientists have concluded that the design is constantly changing. Design as creativity is manifested in object-spatial three-dimensional thinking. Considering the essence of design as a method of creative thinking, researchers point to the universalism of this discipline (Stankevich, 2012).

The rapid advances of graphic design, the acceleration of its measurements of multimedia and interactivity require appropriate changes in curricula and disciplines. The field of graphic and communicative design needs to be 
transformed according to dynamic external changes, in particular the integration of digital technologies in design. It is necessary to understand modern professional tendencies, educational practices and labor market needs in the field of graphic design for the expediency of reforming educational practice (Steinberger, Foth \& Alt, 2014).

Today, access to information has become quite simple thanks to the development of science and technology. As a result of rapid developments in the field of communication technologies, information is becoming more intensive, which facilitates its achievement. The need for information design, the purpose of which is to provide information systematically, is important to save people from the chaos caused by this information intensity, by accurately and quickly transmitting current information to the target recipient. It is a fact that there is a need for information design that everyone can understand nowadays (Aybay, 2017).

The outlined requires research, the object of which is the current state of approaches to the educational process in the field of design at the regional level. This academic paper is aimed at studying the problems of compliance education and market needs, the latest trends in design. The latest trends in design relate to the study of changes in the factors that determine the need to adjust approaches to the educational process: globalization, digital technologies, the growing role of the market economy of education. The outlined factors are both opportunities for the transformation of educational disciplines of graphic design and the practice of providing educational services of formal and informal nature. Studying the regional features of the transformation of approaches to teaching graphic design will provide an understanding of the impact of regional specifics on the educational process.

The purpose of the academic paper centers around studying the state of use of modern approaches to teaching graphic design in terms of the impact of digital technologies and labor market needs on the educational process.

According to the purpose outlined, the objectives of this study are defined, namely:

1. To study the regional specifics of the labor market in the field of graphic design and compliance of educational services with market needs.

2. To carry out a regional analysis of curricula, disciplines specializing in "Graphic Design" and identify their compliance with modern concepts and approaches to design.

3. To consider the evolution of recommendations in teaching graphic design in the context of the transformation of professional trends and competences.

4. To consider the general issues of design and education in the field of graphic design, which have a significant impact on the curricula in the field of design education (Triggs, 2011).

\section{Literature Review}

Visualizer (designer) - the one who translates "blind" texts into visual language. Abstract thinking acquires concreteness and clarity. Nowadays, the most important task of a graphic designer is to make ideas and problems visible and to some extent audible so that they become clear to the consumer in the shortest possible time. Objectivity, intelligibility, universality of visual language allow to transfer information more compactly and to accelerate process of its perception. This process is called visual communication (Vergunov, 2006). Technology provides tools for art, serves the visual design and artistic idea (Rodkin, 2003).

In addition to talent, skills and inspiration, a modern designer can not do without an understanding of basic research methods and approaches, as well as the principles of their application. In order for the efforts you put into working on the project to be appropriate and work for the result, at each stage you need to collect information, correctly interpret it and take it into account. Leonardo and Ambrose (2019) offer an overview of the types and formats of research that will be useful in design practice, allowing you to delve into the context, study the preferences and expectations of the client and audience, and finally choose the appropriate way to convey the designer's ideas (Bart, 1989). Creative thinking is a skill that can be developed, scientists offer theories and strategies that will promote design creativity (Leonardo \& Ambrose, 2019).

The task of a graphic designer is to show the essence of a product or idea, to prepare a background on which it is easier to demonstrate its benefits, to effectively present and disseminate information. In these processes, the style becomes a certain code of tolerance, a signal that it is a message for a specific audience (Geller \& Quast, 2019).

Given the purpose of information, the purpose of effective communication and an interdisciplinary approach, it is clear that information design has the same understanding and character as the design of visual communication. The importance of graphic design and the importance of interdisciplinary cooperation are becoming increasingly visible with the need to develop innovations caused by development technology, and the need to develop the final intensity of information (Aybay, 2017). 
"Information interaction" is a process of interaction with the subject matter and content of the information system. The model of information interaction involves the intersection of the user and the computer system, on the basis of which content is formed in the form of a design with a certain information content (Toms, 2002).

Information interaction is a sphere of studying the processes of interaction with information. Design requires an understanding of human interaction in an integrated aspect. Based on the designer's ideas about the potential product, it is possible to influence the cognitive processes of product users (Yamamoto \& Nakakoji, 2005). Cognitive processes in particular may include analytical thinking, decision making and meaning, learning, problem solving, knowledge seeking and planning (Sedig \& Parsons, 2013). Cognitive work approach is an ecological approach to design that analyzes environmental factors in terms of human interaction with information (Fidel, 2012). In addition to environmental, informational and human approaches to design are distinguished. Thus, the designer has influence and manipulates with tools. Interactive design, accordingly, stimulates or hinders creativity in the initial stages of product creation in information design (Yamamoto \& Nakakoji, 2005).

The aspects of the initial design stages in information design are as follows: externalization tools that influence decision-making by designers concerning design methods; designers create a product based on partial ideas about the final product and external manifestations of ideas; the designer creates externalizations to display the product and interpret it; the project developer makes the transition from the predicted ideas to their gradual revision, confirmation of these ideas (Yamamoto \& Nakakoji, 2005).

In the last century (the 1980s) design was guided by the concept of "direct manipulation" (Marchionini, 2008). Over time, the environmental approach began to dominate in the field of design (Fidel, 2012). With the beginning of the interaction of different disciplines, the approach to design began to change: the concept of "wild theory" has appeared in science, which presupposes the creativity of design. Integration of psychology and computer science into design, the concept of sustainable development and creativity is the reason for the development of quite authentic artifacts. Both in the early 1990s, the researches have proved the penetration of computer science into design and currently other sciences are integrating to form new concepts, knowledge, and approaches to graphic design. The investigations refer to the "disciplinary anxieties" growing around the concept of "Third Wave 'Human Computer Interaction (HCI)" (Bowers, 2012). As a result, the teaching of graphic design is changing. At the same time, the time lag, with which new approaches are introduced into the educational process, determines the level of effectiveness of information interactive design as a discipline.

Rogers $(2011,2012)$ initiated a "wild theory of technologically facilitated behavioral change" that explains the interconnection between informational significance, behavioral phenomena, ethics, and computation. This means the development of transdisciplinary thinking - the combination and extrapolation of different concepts, issues and values in information interactive design. This theory of "wild design" influences on the approaches to the educational process through the integration of its main components into the product of graphic design. The basic components of this theory include informational significance, behavioral phenomena, ethics of communication and computational technologies. These elements will affect the degree of creativity in design, because their consideration when creating the final product can lead to a lack of creativity of the designer at a certain level of skills, professionalism and competence. Curricula should be structured in such a way that the level of projectivity of the designer allows him to take into account all the elements of modern approaches to creating a product while expressing freedom, creativity and imagination. The level of the designer's professionalism determines the level of creativity and the ability to ensure compliance with the requirements of innovative approaches in design when creating a product.

Thus, "wild theory" is a prerequisite for creativity in interactive design, and the external environment is a factor in the transformation of theory, approaches to interactive design as a discipline. Wild theory in interactive design will gradually replace the philosophical approach to creating artifacts in design. Taking into consideration the outlined trends, there is a need to study the impact of the transformation of the discipline of information interactive design in the training process of modern graphic designer (Attfield, 2020).

\section{Data and Research Methodology}

\subsection{Research Design}

The study is based on a qualitative methodology; it contains an analysis of academic disciplines to identify inconsistencies between modern approaches and the educational process. The present investigation is based on the concept of "wild design" of Rogers (2011), which provides an idea of the interaction of modern graphic design with information, behavioral phenomena in society, computation and ethics. The analysis involves a study of the practice of integrating these components of the "wild theory" of design in the process of teaching the discipline of graphic design. 
The basic hypothesis of this study centers around modern approaches that have emerged in response to the needs of the labor market and the integration of technology into the design field. They transform curricula and disciplines in the context of forming a professional designer who is able to think creatively when creating a product.

The next hypothesis refers to the specifics of the regional labor market; it determines the supply of educational services in the field of graphic design.

The next hypothesis centers around the professional competences of a graphic designer, which meet the needs of the labor market, however lag behind new concepts, approaches to the requirements of product creation.

\subsection{Sample Study and Methods}

Based on the study and analysis of recent trends in graphic design as a discipline, the level of transdisciplinarity of modern science has been assessed. An analysis of academic disciplines was conducted within the curricula of "graphic design" in order to study the trends in graphic design. The analysis has been conducted on the basis of the content of five universities of Ukraine, which offer educational qualification level of bachelor, master according to the site rating (Osvita, n.d.). The official websites of the universities have been used for conducting the content analysis, namely: Kyiv University of Culture, Kyiv National University of Culture and Arts (KNUCA), KROK University of Economics and Law, Interregional Academy of Personnel Management (IAPM). The analysis included the generalization of the vision and content of disciplines offered by tertiary educational institutions of Ukraine, the study of methodological recommendations of disciplines within the specialization "Graphic Design and Advertising" (Table 1).

Table 1. Sampling of specialties "022 Design", specialization "Graphic Design and Advertising" for conducting the analysis, 2020

\begin{tabular}{ll}
\hline \multicolumn{1}{c}{ University } & \multicolumn{1}{c}{ Source for analysis } \\
\hline Kyiv University of Culture & http://kuk-university.com \\
Kyiv National University of Culture and Arts (KNUCA) & http://www.knukim.edu.ua \\
KROK University of Economics and Law & http://www.krok.edu.ua \\
Interregional Academy of Personnel Management (IAPM) & http://www.maup.com.ua \\
\hline
\end{tabular}

Source: it has been compiled by the author

Data on the skills required by employers have been used to compare the relevance of curricula to the needs of the labor market. The site Work.ua (n. d.) was the source of information.

Based on the analysis of the content of disciplines within the specialization "graphic design and advertising", theoretical and methodological concepts of modern practice of information interactive design have been formed.

\subsection{Research Limitations}

There is no detailed analysis of disciplines in this academic paper due to the different content of the official websites of formal education universities. Non-formal education and training courses for graphic designers have not also been taken into account due to the focus of the research on a wider range of graphic design disciplines. It was not possible to compare the competences and knowledge of the future graphic designer due to the unavailability of information on the websites of some universities on teaching methods, disciplines and skills of designers in the course of training graphic designers. Therefore, it was not possible to fully assess the regional specifics of educational curricula of universities and fully accurately describe whether the learning process corresponds to modern approaches to graphic design (Rogers \& Marshall, 2017).

\section{Results and discussion}

4.1 Regional Specifics of the Labor Market in the Field of Graphic Design and Compliance of Educational Services with Market Needs

The Ukrainian market offers formal and informal educational services in the field of graphic design. The average salary of a graphic designer amounts $15000 \mathrm{UAH}$ per month. There are 503 vacancies on the website Work.ua (n. d.) with a description of the basic requirements for a professional, one of which is compliance with standards and at the same time creativity.

On average, a graphic design specialist in Ukraine receives the salary of 15000 UAH (Figure 1, according to 1051 vacancies on the site Work.ua (n.d.) for the last three months). The analysis has included the headings "Designer" and "Designer's Assistant". 


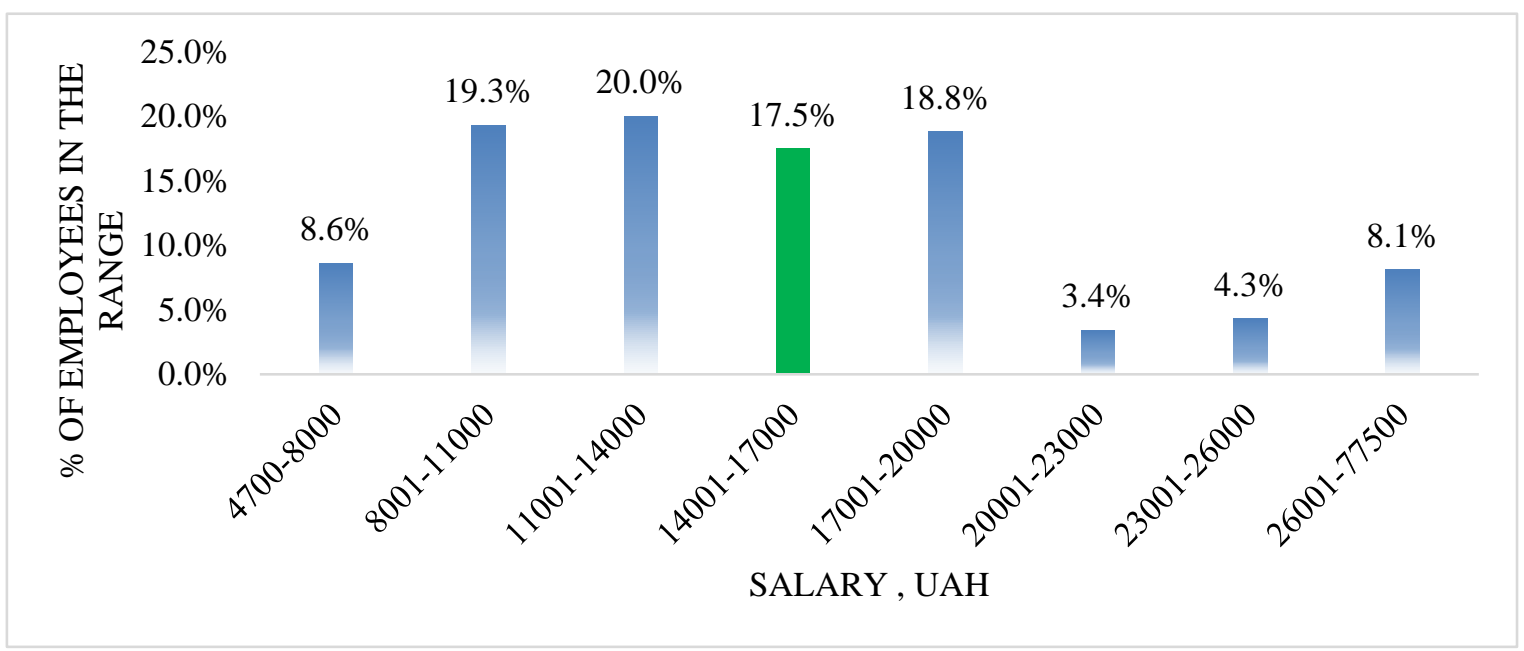

Figure 1. Distribution of salaries of a graphic designer

Source: Work.ua (n.d.)

At first glance, these requirements contradict each other, however, a professional designer, obtaining a set of standard skills and competences, is able to ensure clarity of standards and only then create a creative product.

The labor market requires the following hard skills of a graphic designer, namely:

1. Skills and abilities of working in graphic design software: Adobe Photoshop, Illustrator, Corel Draw, InDesign;

2. Innovative thinking, creativity;

3. Ability to defend their own ideas ("soft skills");

4. Command of English in case of intention to work with foreign companies.

5. Depending on the requirements of employers to the graphic designer, there are requirements for knowledge in the field of psychology (for example, UX-designer), the fundamentals of resistance of materials (for example, industrial designer) (Heller, 2015).

If we compare with the skills and competences, formed by universities, it can be noted that the needs of the labor market are met by available educational services, that is, there is a correspondence between the skills needed by employers and the skills developed by the university (Table 2).

Table 2. Correspondence of professional competences of a graphic designer to the needs of the labor market

\begin{tabular}{ccc}
\hline $\begin{array}{c}\text { Professional } \\
\text { competences of a } \\
\text { graphic designer }\end{array}$ & $\begin{array}{c}\text { Competences acquired in the process of studying at the } \\
\text { university }\end{array}$ & $\begin{array}{c}\text { Competences required by the } \\
\text { labor market }\end{array}$ \\
\hline
\end{tabular}

\begin{tabular}{|c|c|c|}
\hline \multirow{4}{*}{$\begin{array}{l}\text { Kyiv University of } \\
\text { Culture }\end{array}$} & Work in computer graphics software; & Skills and abilities of working \\
\hline & $\begin{array}{l}\text { Design of web-sites and game elements; } \\
\text { Creation of illustrations, art projects, animations, } \\
\text { typographics; }\end{array}$ & $\begin{array}{l}\text { in graphic design software: } \\
\text { Adobe Photoshop, Illustrator, } \\
\text { Corel Draw, InDesign. }\end{array}$ \\
\hline & Advertising products in visual manifestations of all types; & $\begin{array}{l}\text { Innovative } \\
\text { creativity. }\end{array}$ \\
\hline & $\begin{array}{l}\text { Layout, printing design. } \\
\text { Development of corporate identity, packaging and labels. }\end{array}$ & $\begin{array}{l}\text { Ability to defend their own } \\
\text { ideas ("soft skills"). }\end{array}$ \\
\hline $\begin{array}{l}\text { KROK University } \\
\text { of Economics and } \\
\text { Law }\end{array}$ & $\begin{array}{l}\text { Knowledge of compositional construction of design objects, } \\
\text { ergonomics and artistic design, skills in design and } \\
\text { manufacturing technologies of design objects, design }\end{array}$ & $\begin{array}{l}\text { Command of English in case } \\
\text { of intention to work with } \\
\text { foreign companies. }\end{array}$ \\
\hline
\end{tabular}


for the future design object.

Rules of work with office equipment and publishing and printing equipment; modern packages of applied graphic and office software (Adobe Illustrator, Adobe Photoshop, Adobe

Interregional

Academy

Personnel

Management

(IAPM)
CorelDraw, 3D-MAX, ArchiCAD, AutoCAD, Revit, etc.);

of general methods of design and its specific differences in the

field; principles of providing social-cultural needs, organization of project activities, conducting pre-project research;

methodology for formulating modern requirements for creating a design concept; integrated system approaches to design processes.

Source: the author's research.

The most complete description of the knowledge, received by the student, is specified on the IAPM website. It is worth emphasizing that the university offers comprehensive system approaches to processes, procedures, design rules (methods of expert analysis of project tasks, substantiation and qualitative implementation of single and complex design projects based on the synthesis of logical and imaginative thinking). IAPM also forms knowledge concerning the patterns of processes of reflection of the spatial subject environment through the prism of its own worldview, creative design concepts. This means that curricula take into account both the need of the labor market for professional competences and creativity and a creative approach to creating graphic design products.

\subsection{Regional Analysis of Curricula: Modern Concepts, Approaches in the Disciplines of Graphic Design}

The study of the practice of universities in the process of training modern graphic designers indicates the use of information technology in the creation of artifacts. Institutions specialize in providing knowledge and creating design. For instance, Kyiv University of Culture offers the study of computer graphics softwares, design of web-sites and game elements, the study of creating illustrations, art projects, animation, typographics; study of advertising visualization, creation of layouts and design of printed products, development of corporate identity, packaging and labels. Accordingly, the theory of "wild design" of Western schools is not reflected in the curricula of tertiary educational institutions of Ukraine. Information interactive design is not a separate discipline within graphic design, and graphic design is complemented by disciplines related to advertising. Accordingly, in Ukraine, design as a wild concept is created on the basis of the market's need for specialists; elements of creativity are present, however elements of the latest Western theories are not typical.

Curricula contain a number of disciplines that involve the study of software program to create a product. For instance, at Kyiv National University of Culture and Arts (KNUCA) disciplines within the specialization "Graphic Design and Advertising" include design in graphics, modeling, layout, study of computer technologies for the design of printing products, packaging, labels, training in advertising communications. The needs of the Ukrainian market in graphic products determine the offer of a set of educational services of universities: the educational market is focused on the labor market, and, therefore, technical and technological skills prevail over the development of students' creativity.

At the same time, elements of creativity, as an important component of "wild design" at Kyiv National University of Culture and Arts (KNUCA) are contained in a wide range of different ways, tools for "formation of visual expressions". This makes it possible for graphic designers to freely convey content, the essence of information messages depending on their level of complexity. This means that creativity as an element of "wild design" is manifested in the formation in the learning process of creative thinking in order to accurately convey the essence of the information message. Creativity in this case is subject to certain frameworks; in particular, these frameworks are determined by the information that requires the transfer of information to consumers.

The next element of information interactive design is the environmental component. The study of disciplines of tertiary educational institutions allows us to conclude that the direction of the educational process to achieve the goal of forming professional designers does not correspond to the environmental approach. Orientation to the labor market is the cause of insufficient environmental compatibility of disciplines. As a result, modern graphic designers have professional skills, however, there are doubts about their environmental orientation in the process of creating a product. 
Low level of wages and other social-economic issues of Ukraine affect the degree of environmental compatibility in the creation of products (Table 3 ).

Table 3. Vision and disciplines of Ukrainian universities according to specialization "Graphic design and advertising" or "Design", 2020

\begin{tabular}{|c|c|c|}
\hline University & Vision & $\begin{array}{c}\text { Disciplines of specialization "Graphic design and } \\
\text { advertising" or "Design" }\end{array}$ \\
\hline $\begin{array}{l}\text { Kyiv University of } \\
\text { Culture }\end{array}$ & $\begin{array}{l}\text { "Modern design is a type of } \\
\text { professional activity that } \\
\text { aestheticizes and comforts all } \\
\text { spheres of human life". }\end{array}$ & There is no list of disciplines \\
\hline $\begin{array}{l}\text { Kyiv National } \\
\text { University of Culture } \\
\text { and Arts (KNUCA) }\end{array}$ & $\begin{array}{l}\text { Free and variable mastering of } \\
\text { design and graphic language; } \\
\text { learning to reflect emotions, } \\
\text { moods, feelings, etc. }\end{array}$ & $\begin{array}{l}\text { Design-engineering in graphics, technical graphics, } \\
\text { project graphics, fonts, layout and modeling, } \\
\text { computer technology in graphic design, design of } \\
\text { printing products, packaging and label design, } \\
\text { advertising communications. }\end{array}$ \\
\hline $\begin{array}{l}\text { KROK University of } \\
\text { Economics and Law* }\end{array}$ & $\begin{array}{l}\text { Formation of creative style and } \\
\text { ability to use modern computer } \\
\text { and information technologies. }\end{array}$ & $\begin{array}{l}\text { "History of design", "Painting", "Drawing", } \\
\text { "Fundamentals of composition and coloristics", } \\
\text { "Fundamentals of shaping", "Layout and modeling", } \\
\text { "Computer modeling of clothes", "Materials } \\
\text { science", "Branding and portfolio", "Fundamentals } \\
\text { of design". }\end{array}$ \\
\hline $\begin{array}{l}\text { Interregional } \\
\text { of } \\
\text { Management (IAPM) }\end{array}$ & $\begin{array}{l}\text { "Artistic design of a } \\
\text { harmonious and functionally } \\
\text { perfect human environment" }\end{array}$ & $\begin{array}{l}\text { Font art, arts and crafts, form making, graphic } \\
\text { techniques and materials, typographics, psychology } \\
\text { of advertising, advertising design. }\end{array}$ \\
\hline
\end{tabular}

Source: the author's research

* - University offers educational services under the curriculum "Design"

Content analysis of academic disciplines within the specialization "graphic design" shows the lack of disciplines in universities related to the study of the psychology of graphic design. At the same time, IAPM offers the study of the psychology of advertising within the specialization. In addition, it has been stated on the IAPM website that "The basic purpose of the specialty is to train qualified personnel to solve complex problems and issues in the field of design. Within the specialty, graduates acquire in-depth knowledge and skills of an innovative nature, and the level of their intellectual potential is sufficient to solve professional issues".

In universities, teaching is based on the classic concept of environmental design, and the disciplines provide students with knowledge and skills to master the profession and develop "hard skills". Herewith, students" "soft skills" are limited due to the need to acquire skills in computer software. For instance, IAPM provides employment opportunities as a technician-designer, colorist, advertising agent, etc. At the same time, IAPM uses complex system approaches to design processes "from methods of expert analysis of project tasks to substantiation and qualitative implementation of single and complex design projects based on the synthesis of logical and creative thinking". IAPM provides students with knowledge about the "conformity to principle of the process of reflection of the spatial-objective environment through the prism of their own worldview and creative design concepts". At the same time, the level of educational services lags far behind the quality of education in Western universities, where a transdisciplinary approach prevails and develops.

Kyiv University of Culture with its mission determines the development of professional competences of graphic designers in order to aestheticize and comfort people's lives. Kyiv National University of Culture and Arts (KNUCA) defines a similar vision: students should gain skills in project-graphic language. Learning to reflect emotions, moods, feelings concerns the formation of skills to reflect these elements in information interactive products. Interregional Academy of Personnel Management (IAPM) defines the vision as "artistic design of a harmonious and functionally perfect human environment". 
This means that the theory of "wild design" in Ukraine combines two elements: informational significance and computation. Such elements as behavioral phenomena and ethics are poorly integrated into the specialization "Graphic Design and Advertising". Conceptualization of the practice of teaching disciplines for the training of modern graphic designer makes it posible to form a modern paradigm of information interactive design. The idea of Ukrainian graphic design as a discipline centers around forming a competent professional with technical skills in order to develop business-oriented products in the field of graphic design.

Analysis of curricula and disciplines of universities shows that a systematic and integrated approach is used in the proccess of training graphic designers. These approaches correspond to manipulative, ecological approaches as the basic theories of creation of a graphic product. At the same time, the theory of "wild design" is not reflected in the modern practice of teaching disciplines within the specialization "graphic design". This is due to the lack of understanding for the development of such disciplines that would ensure the formation of skills to create a "wild product".

\subsection{Evolution in Teaching Graphic Design in the Context of Transformation of Professional Tendencies and Competences}

Taking into consideration the fact that in 1980-1990 the approach of "manipulative" creation of designer products was widespread, interactive information design was aimed at technical ways of creating products. This involved the transmission of an information message in the design, aimed at influencing the human mind to make decisions about purchasing a product. Such influence was carried out for commercial purposes. Accordingly, the recommendations in teaching graphic design concerned the development of disciplines that would provide the graphic designer with knowledge of product psychology, ability to use technical programs, design and engineering skills, manufacturing technology, knowledge of design graphics, knowledge of coloristics, etc (Kim et al., 2016).

With the beginning of the integration of the ecological approach to design, the development of technology in the creation of products design takes into account the needs of human as a consumer of information. The consumer's understanding of commercial design goals has led to a change in design approaches that guide design product developers. Consequently, completely simple clear company logos appear (Figure 2), and creativity and creative approach to creating products becomes one of the main requirements for a modern graphic designer. That is why "soft skills" are added to technical skills, and curricula take into account the need of the labor market for creativity, creative thinking. As a result, the list of disciplines includes those that develop the creativity of a graphic designer.

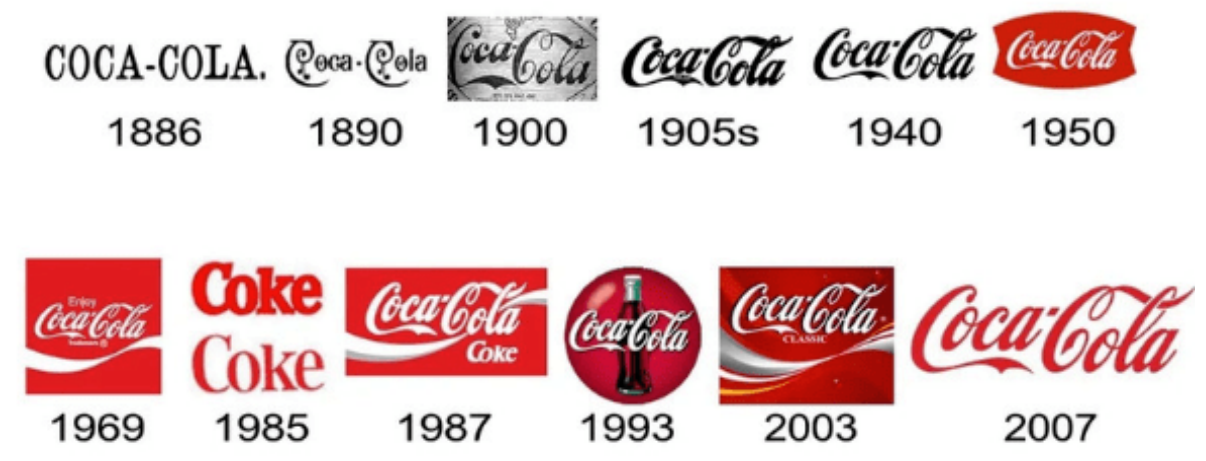

Figure 2. History of the Coca-Cola logo

Source: Ukrainian telecommunication portal (n. d.)

The purpose of creating a clear design product is to focus on the product, but at the same time to influence the consumer of information to remember the product. (Figure 2).

The "wild theory" of design is a completely new concept, because it provides the creation of a product that is beyond imagination; it invites the consumer to look at the design product with a new viewpoint. As a result, graphic products with "fresh" features appear, which are simultaneously filled with information content as well as provide interactivity, simplicity, and memory by consumers of information. Nowadays curricula do not take into account the elements of "wild design", because it is extremely difficult to create a "wild" product that will provide a new perspective of the consumer with the same information message. Creation of a new product depends solely on the personal qualities of the graphic designer. The authors of the academic paper are of the opinion that technical skills and creativity can be 
developed in the process of obtaining education and practical activities. However, the personal qualities required to create a "wild product" are almost impossible to develop only on the basis of skills that are formed in the process of learning / working. The skills and competences of a "wild designer", who is able to create a fresh viewpoint at the same product, will be the result of the formation of an experienced graphic designer with a creative analytical mindset and honed technical skills in the future. Therefore, the development of personal qualities of such a designer depends solely on his motivation and knowledge.

4.4 General Problems of Design and Education in the Field of Graphic Design, which have a Significant Impact on the Curricula in the Field of Design Education

The study of curricula and disciplines makes it possible to conclude that the basic problems of design and education in the field of graphic design are the nonconformity between the goals of developers of graphic products and the goals of consumers of graphic products. Universities understand the needs of developers, so they form the designer's the skills required by the market - technical and creative skills, competences. Education in the field of design adapts to the practice of design, albeit with a time lag (dropping behind). The time lag is evidenced by a certain discrepancy in "wild theory" as a new concept and the approaches used in teaching graphic design. At the same time, the needs of consumers of information are not always taken into account through the commercialization of the graphic product. Another problem refers to the fact that developers and universities do not sufficiently understand the needs of information consumers, and a manipulative approach is still present in graphic design products.

\section{Conclusions}

The conducted investigation makes it possible to partially confirm the hypothesis that modern approaches that have emerged in response to the needs of the labor market, the integration of technology into design, transform curricula and disciplines. As a result, curricula provide training of a professional designer who is able to think creatively when creating a product. Learning graphic design tardily meets the requirements of the labor market.

The specifics of the regional labor market determines the offer of educational services in the field of graphic design. Thus, the Ukrainian market of educational services is characterized by the use of integrated and systematic approaches to learning. Complexity means a combination of technical skills and creativity. The outlined skills are needed in the job market to develop a design product. The professional competences of a graphic designer meet the needs of the labor market, however lag behind new concepts, approaches to product requirements. For instance, curricula currently do not take into account the elements of "wild design". This is due to the difficulty of creating a "wild" product that will provide a new consumer's viewpoint of the graphic product with the same information message. Despite the development of a "wild" concept for the creation of designer products, this area has been little studied in terms of integration into the educational process. The problem of modern graphic design is the commercialization of the final product, which, despite the development of approaches, aims to influence the consciousness of the consumer of the information message. Education meets the needs of design developers in the technical creative skills of designers, while the consumer is a managed entity in this field.

\section{References}

Attfield, J. (2020). Wild things: The material culture of everyday life. London, UK: Bloomsbury Publishing.

Aybay, C. (2017). Inter-disciplinary design in information design cooperation and the place of graphic design in this collaboration. The Turkish Online Journal of Design, Art and Communication - TOJDAC, 7(3), 454-462. https://doi.org/10.7456/10703100/008

Bart, R. (1989). Selected works: Semiotics: Poetics. Moscow, Russia: Progress.

Bowers, J. (2012). The logic of annotated portfolios: Communicating the value of research through design'. Proceedings of the Designing Interactive Systems Conference (pp. 68-77). New York, NY: Association for Computing Machinery. https://doi.org/10.1145/2317956.2317968

Fidel, R. (2012). Human information interaction: An ecological approach to information behavior. Cambridge, UK: Mit Press. https://doi.org/10.7551/mitpress/9780262017008.001.0001

Geller, S. \& Quast, S. (2019). Graphic styles: From Victorians to hipsters. Kyiv, Ukraine: ArtHuss.

Heller, S. (2015). The education of a graphic designer. New York, NY: Simon and Schuster.

Kim, N. W., Schweickart, E., Liu, Z., Dontcheva, M., Li, W., Popovic, J. \& Pfister, H. (2016). Data-driven guides: Supporting expressive design for information graphics. IEEE transactions on visualization and computer graphics, 23(1), 491-500. https://doi.org/10.1109/TVCG.2016.2598620 
Leonardo, N. \& Ambrose, G. (2019). Fundamentals. Graphic design 02: Design research. Kyiv, Ukraine: ArtHuss.

Marchionini, G. (2008). Human-information interaction research and development. Library \& Information Science Research, 30(3), 165-174. https://doi.org/10.1016/j.lisr.2008.07.001

Osvita. (n.d.). Higher Education Universities Digest. Retrieved from https://osvita.ua/vnz/guide/search-17-0-0-56.html

Rodkin, P. (2003). New visual perception: Modern visual art in the conditions of a new perceptual challenge. Moscow, Russia: Yunost.

Rogers, Y. (2011). Interaction design gone wild. Interactions, 18(4), 58. https://doi.org/10.1145/1978822.1978834

Rogers, Y. (2012). HCI theory: Classical, modern, and contemporary. Synthesis lectures on human-centered informatics, 5(2), 1-129. https://doi.org/10.2200/S00418ED1V01Y201205HCI014

Rogers, Y. \& Marshall, P. (2017). Research in the Wild. Synthesis Lectures on Human-Centered Informatics, 10(3), 97. https://doi.org/10.2200/S00764ED1V01Y201703HCI037

Sedig, K. \& Parsons, P. (2013). Interaction design for complex cognitive activities with visual representations: A pattern-based approach. AIS Transactions on Human-Computer Interaction, 5(2), 84-133. https://aisel.aisnet.org/thci/vol5/iss2/1 https://doi.org/10.17705/1thci.00055

Stankevich, M. (2012). Protodesign, design concepts and morphology. Essays on the history of Ukrainian design of the twentieth century: Collection of articles. Kyiv, Ukraine: Phoenix.

Steinberger, F., Foth, M. \& Alt, F. (2014). Vote with your feet: Local community polling on urban screens. In Proceedings of The International Symposium on Pervasive Displays, 44-49. https://doi.org/10.1145/2611009.2611015

Toms, E. G. (2002). Information interaction: Providing a framework for information architecture. Journal of the American Society for Information Science and Technology, 53(10), 855-862. https://doi.org/10.1002/asi.10094

Triggs, T. (2011). Graphic design history: Past, present, and future. Design Issues, 27(1), 3-6. https://doi.org/10.1162/DESI_a_00051

Ukrainian telecommunication portal. (n. d.) History of the Coca-Cola logo: How a successful logo was create. Retrieved from https://portaltele.com.ua/news/companies/istoriya-logotipa-coca-cola-kak-sozdavalsya-uspeshnyj-logotip.html

Vergunov, S. V. (2006). On the question of design and visualization problems. Instrumental aspect. Bulletin of the Kharkiv State Academy of Design and Arts, 4, 10-15.

Work.ua. (n. d.). Retrieved from https://www.work.ua/career-guide/designer/

Yamamoto, Y. \& Nakakoji, K. (2005). Interaction design of tools for fostering creativity in the early stages of information design. International Journal of Human-Computer Studies, 63(4-5), 513-535. https://doi.org/10.1016/j.ijhcs.2005.04.023 